\title{
Blood and Blood Components: From Similarities to Differences
}

\author{
Olivier Garraud ${ }^{1,2 *}$ and Jean-Daniel Tissot ${ }^{3,4}$ \\ ${ }^{1}$ Faculty of Medicine, University of Lyon, Saint-Etienne, France, ${ }^{2}$ Institut National de la Transfusion Sanguine, Paris, France, \\ ${ }^{3}$ Transfusion Interrégionale CRS, Epalinges, Switzerland, ${ }^{4}$ Faculty of Biology and Medicine, University of Lausanne, \\ Lausanne, Switzerland
}

\section{OPEN ACCESS}

Edited by:

Meral Beksac,

Ankara University, Turkey

Reviewed by:

Anastasios G. Kriebardis, Technological Educational Institute of Athens, Greece

Pervin Topçuoğ/u,

Ankara University Medical School, Turkey

*Correspondence: Olivier Garraud ogarraud@ints.fr

Specialty section:

This article was submitted to Hematology,

a section of the journal

Frontiers in Medicine

Received: 01 December 2017 Accepted: 16 March 2018 Published: 09 April 2018

Citation:

Garraud O and Tissot J-D (2018) Blood and Blood Components: From Similarities to Differences. Front. Med. 5:84. doi: 10.3389/fmed.2018.00084
Blood transfusion is made possible because, in most countries and organizations, altruistic individuals voluntarily, anonymously, and generously donate (without compensation) either whole blood or separated components that are then processed and distributed by professionals, prior to being allocated to recipients in need. Being part of modern medicine, blood transfusion uses so-called standard blood components when relative to cellular fractions and fresh plasma. However, as will be discussed in this paper, strictly speaking, such so-called labile blood components are not completely standard. Furthermore, the prevalent system based on voluntary, non-remunerated blood donation is not yet universal and, despite claims by the World Health Organization that $100 \%$ of blood collection will be derived from altruistic donations by 2020 (postponed to 2025), many obstacles may hinder this ambition, especially when relative to the collection of the enormous amount of plasma destined for fractionation into plasma derivative or drugs. Finally, country organizations also vary due to the economy, sociology, politics, and epidemiology. This paper then, discusses the particulars (of which ethical considerations) of blood transfusion diversity and the consequences for donors, patients, and society.

Keywords: transfusion, blood donation, blood processing, blood components, ethics

\section{INTRODUCTION}

Blood and blood components (BCs) for transfusion chiefly originate from donations made by altruistic individuals. However, although $100 \%$ voluntary non-remunerated blood donation (VNRD) is the goal that has been set (by 2020 as publicized by the World Health Organization WHO-later revised to 2025 in some areas) $(1,2)$, it is far from being achieved at the present time for various reasons linked to contingency (3), and the emergence in low/middle-income countries of modern health-care services requiring more transfusion prescriptions. Blood for therapeutic use comes into two sets: (1) the one consists in labile blood components (LBCs) comprising essentially the cellular components [red blood cells concentrates (RBCCs) and platelet concentrates, PCs as well as part of therapeutic plasma, principally fresh frozen plasma FFP]; and (2) the other one consists in plasma derived or fractionated drugs, and occasionally in FFP obtained from large pools and subjected to stringent pathogen reduction. While the former is principally handled by blood establishments (BEs), many of them overruled by the public sector or Non Governmental, non-for-profit, organizations such as the Red-Cross/Red-Crescent, the latter is largely handled by the plasma fraction industry within the private, for-profit sector.

Labile blood components are usually labeled as "standard blood products," and thus refer to guidelines such as the Council of Europe's "Guide to the preparation, use and quality assurance of blood components" (4). However, all LBCs referring to the same label are, in fact, significantly 
different from each other: they depend on the donor, the process and the storage characteristics which are not consistent, as each consists either in single donor originating units or small pools ( 5 in mean, and $>12$ by all means); minipools apply to PCs and therapeutic plasma. Indeed, as each LBC reflects both the genetic and non-genetic-based characteristics of the donors (referred to as "storage lesions"), they all differ from one another despite considerable efforts made to minimize deviations in their process.

This paper will briefly outline the most visible community forms of and differences in LBCs, and the way in which differences can affect outcomes in: (1) recipients; (2) health policies and economics (as essential additional safety procedures can result in even more complex disparities between LBC inventories). The circumstances of blood collection and how ethics are concerned when blood supply does not meet demand or when marketing creates new markets will also be discussed.

\section{AS THE ESSENTIAL DETERMINANT IN TRANSFUSION, BLOOD REPRESENTS A COMMON MATTER FOR HUMANS}

Every human depends on nearly normal blood functions to survive. Moderate alterations may result in sub-physiological functioning, while more severe defects can be corrected by either drugs or blood derivatives (when available), or both, pending anticipated gene correction. Blood characterizes species and cannot be safely exchanged between species, even close ones such as humans and apes. Human blood transfusion can nevertheless be processed within the human species provided major compatibility rules are respected. This property first allowed blood transfusion to be performed in emergency situations, and later, with technological advances, to be applied almost routinely, despite the fact that "routine" is a word that never applies to blood transfusion from either the donor's or the recipient's perspective $(5,6)$.

Donated blood is humanity $(7,8)$ and ideally, VNRD blood is "pure" humanity, yet replacement donation shares the values of assistance and cannot be considered non-altruistic, even if a certain degree of social pressure cannot be ruled out (3). Maybe the lowest common denominator is the root symbol of blood, its sacred characteristic, whatever sacred may mean to people, ranging from religious to atheistic sentiments (9). Thanks to initiatives like Blood Donor Day on the 14th of June, it can be acknowledged on the highest scale that many people worldwide share the idealistic human view of blood donation for transfusion purposes (10). Ideally, this standpoint should make sure that such a process expands and infuses in areas where VNRD is not yet achievable. However, the situation is far from universal or exemplary. Three taints can be outlined as follows: (1) as the demand for BCs expands in many countries, BEs start applying marketing methods to attain prospective new blood donors, potentially altering the voluntary aspect of donation, or the benevolence (or the absence of profit) (11). The same holds true for plasma collectors within the industry (12-16). (2) The benefits of blood have been distorted to serve non-life-threatening medical conditions, and BCs have entered the for-profit market and business where blood is being increasingly used in welfare clinics for doping or cosmetic applications $(17,18)$. This merchandized blood may, therefore, no longer be available for therapeutic and medical indications, potentially worsening the shortage problem and ultimately leading BEs to use enhanced marketing tools and enter a vicious circle. (3) Blood and BCs for research now represent an expanding market, they can either be "conventional" as BEs trade left-overs from test tubes or residues from blood processing, or BCs purposefully processed, i.e., BEs collect blood from VNRDs not eligible for the therapeutic pathway or presenting characteristics required for specific research. In those cases, VNRDs are usually informed that all or part of their donation will be used for research programmes and they may object to this use. Moreover, some donors sell blood for specific research programmes, with the blood generally being collected outside of BEs; this is possible in some countries but is strictly forbidden in others. Research ethics committees would prevent these possibilities.

\section{SIMILARITIES OF HUMAN BLOOD}

As has already been outlined, one common platform for humans considering blood is the general anthropological consideration of this "fluid" which is both material (the blood tissue) and spiritual or the like (altruism, attraction/repulsion, life and death, genetics and lineages, war and peace, and so forth) (9). Regarding its materiality, human blood is unique to the species, and there is by no means any significant difference between ethnic groups, which refutes previous racist theories on the purity of blood. There are indeed certain variations that vary in their frequency in ethnic groups as will be presented in the next section of this paper, but none of them prevent donated blood from being issued to any other human, apart from major $(\mathrm{ABH})$ blood (in fact, tissue) antigen group compatibility. These fundamental characteristics allow the principle of blood transfusion and, moreover, of universal blood transfusion, once the major restriction of the $\mathrm{ABH}$ system is taken care of.

\section{DIVERSITIES IN HUMAN BLOOD AND BCs FOR TRANSFUSION}

In contrast to what has been presented above, no siblings have identical blood. Indeed, even monozygotic twins display genetic and epigenetic differences. Whereas the Mendelian distribution of HLA antigens is transmitted in blocks (haplotypes), HLA diversity between humans ranges from between $10^{6}$ and $10^{7}(19)$. HLA polymorphism limits, to some extent, platelet and leukocyte availability and may also create complications such as immunization (20). Platelet antigens add diversity by bringing more than 30 additional groups often with two alleles each (about 5 matter essentially in transfusion) $(21,22)$. The diversity of erythrocyte antigenic alleles is not only huge (by the thousands) but is also non-haplotypic, offering a tremendous assortment of individual cell markers which is fascinating if we consider the uniqueness of each human, but limits the possibility of matching blood groups for transfusion (23). In fact, half a dozen such antigens are considered routine, allowing for wide-scale transfusion. It should be noted that not all individuals are equal and some individuals 
can be easily transfused (the vast majority) while others with rare blood groups cannot, requiring special programs with technical, ethical, and organizational problems. Similarly, there is diversity in people's propensity to become alloimmunized after blood transfusion, because HLA loci make people good or bad responders to RBC, platelet, or leukocyte antigens (a common law in innate and adaptive immune responses that varies in individuals) (24-26).

With respect to LBCs, despite being called "standard," and their largely similar appearance category by category, they are not, in fact, all the same. They are defined as standard because they fall within a range of maximum and minimum levels of either desired and undesired constituents, and only a few parameters are evaluated among the thousands of variables that make individuals' blood differ from another (4). Furthermore, for each category of LBC, besides the genetic variations between donors that transfer characteristics to the donated component (gender, tissue and HLA genotype, erythrocyte antigen genotype, platelet antigen genotype, protein variants, etc.), there are additional variation parameters that depend on the donors: the time of donation (morning, afternoon, after a meal or fasting, drug and dietary supplement intake, menstrual cycle for non-menopaused women, diet, hygiene habits, and many other parameters) (27-29). All of these parameters may influence the final characteristics of the LBC, though there is no evidence as yet of the effect apart from the presence of soluble antibodies against blood cell antigens (iso-anti-A or B; anti-HLA in females who have been pregnant). BEs extend the variety since the addition and diversification of devices, machines and automats multiply heterogeneity (Table 1 aims to illustrate this). Finally, shelf-life duration multiplies LBC delivery diversity by 41 for RBCCs (in theory: 42 minus 1 day, as 1 day is needed to obtain all the parameters allowing the labeling and issue of the RBCC) (30) and 4 (5 minus 1 day) for PCs. It has further been noticed near two decades ago that RBCs do not recirculate the same depending on storage conditions of the component (one $1 / 4$ of the infused RBCs even never recirculate) (31).

What then is the clinical relevance of such diversity? The case of storage lesions has been extensively studied (32-34), having basically identified two sets of lesions: reversible and irreversible lesions (35). Conflicting data have been obtained from both experimental and clinical data, sparking disputes over the rationale for using fresh as opposed to old blood (36-38). In simple terms, it appears that neither fresh nor old blood is clearly defined, nor is the readout (patient outcome) providing conclusive information, and relevant clinical trials are still needed to resolve this issue (39-41). This issue is of utmost importance as it may revoke the current blood-banking paradigm (meaning that conflicts of interest when blood banks happen to be research principal investigators are non-negligible).

\section{DISPARITIES IN PUBLIC HEALTH POLICIES}

Labile blood components are not considered univocal in various countries and systems, though they are not considered to be drugs according to Directive 2002/98/EC (42), in contrast to plasma fractions or derivatives [Directive 2001/83/EC (43)], or industrially
TABLE 1 | Parameters having proven or theoretical influence on the quality of the processed blood component (BC)

\begin{tabular}{|c|c|c|}
\hline $\begin{array}{l}\text { Main } \\
\text { categories }\end{array}$ & Main items adding diversity & Level of diversity \\
\hline $\begin{array}{l}\text { Donor } \\
\text { dependent } \\
\text { parameters } \\
\text { (genetically } \\
\text { controlled) }\end{array}$ & $\begin{array}{l}\text { - Sex/gender } \\
\text { - Immunogenetic characteristics (blood } \\
\text { groups) } \\
\text { - Natural iso-antibodies } \\
\text { - ... }\end{array}$ & $\begin{array}{l}\text { - Two } \\
\text { - By the thousands } \\
\text { (millions if applied } \\
\text { also to HLA } \\
\text { antigens) } \\
\text { - Variable }\end{array}$ \\
\hline $\begin{array}{l}\text { Donor } \\
\text { dependent } \\
\text { parameters } \\
\text { (only partly } \\
\text { genetically } \\
\text { controlled) }\end{array}$ & $\begin{array}{l}\text { - Immunization status } \\
\text { - Nutrition, metabolism } \\
\text { - Hygiene and intoxications (therapeutic } \\
\text { and recreational drugs, supplements, } \\
\text { alcohol, tobacco) } \\
\text { - Meal; or fast } \\
\text { - Nycthemeral cycle } \\
\text { - Genital cycle and periods } \\
\text { - Outside temperature condition } \\
\text { - ... }\end{array}$ & $\begin{array}{l}\text { Hundreds of } \\
\text { influential parameters }\end{array}$ \\
\hline $\begin{array}{l}\text { Donor } \\
\text { independent } \\
\text { parameters } \\
\text { (BC } \\
\text { processing) }\end{array}$ & $\begin{array}{l}\text { - Shipping time and temperature } \\
\text { - Needles, plastics and bags, } \\
\text { rotators, automats for collection and } \\
\text { intermediate storage } \\
\text { - Devices for cell separation } \\
\text { - Working temperature } \\
\text { - Additives (anticoagulant, solutions, } \\
\text { pathogen inactivation, etc.) } \\
\text { - Filtration steps (meshes, temperature, } \\
\text { timing, etc.) } \\
\text { - Pooling steps } \\
\text { - Preservation conditions } \\
\text { - Physical interactions in shelf-life } \\
\text { conditions (stacking, shocks, thermic } \\
\text { differences, shipping, etc.) }\end{array}$ & $\begin{array}{l}\text { - Variable } \\
\text { - Dozens influential } \\
\text { parameters }\end{array}$ \\
\hline $\begin{array}{l}\text { Patient } \\
\text { (recipient, } \\
\text { beneficiary) } \\
\text { dependent } \\
\text { parameters }\end{array}$ & $\begin{array}{l}\text { - Blood group } \\
\text { - Immunization status } \\
\text { - Matching conditions }\end{array}$ & - By the thousands \\
\hline
\end{tabular}

Each parameter being independent from the preceding one, diversity is created by the multiplication as opposed to the addition of all. The final diversity goes by the million or more. Not all parameters are equally influential but it clearly appears from the table that one given BC collected by one individual, despite being "standardized" to a norm, is unlikely to be "standard."

prepared and solvent-detergent secured therapeutic plasma originating from large pools. Some national regulations do, however, consider labile LBCs to be drugs, as is the case in Switzerland; and WHO recently (2015) added blood and blood derivatives to its list of essential medicines (44). Semantics between medicines and drugs are imprecise, however, and this decision has displeased a number of blood donor associations who are batting against confusion with LBCs and plasma derivatives (45). Furthermore, the logistics by which certified LBCs can be delivered to patients varies considerably between countries: according to the European directive, there are basically two main actors: BEs which collect, process, test, and distribute BCs, and Hospital Blood Banks or HBBs which acquire LBCs from BEs, build up an inventory and deliver selected LBCs to patients upon ad hoc immunohaematological matching (4). On some occasions, $\mathrm{BE}$ and $\mathrm{HBB}$ functions can be held by the same entity (as, e.g., in France). 
In addition, Council of Europe directorate EDQM requests that BEs apply a minimum platform for blood testing, with additional options for BEs willing to raise the LBC safety level with, for example, the implementation of nucleic acid testing (NAT) (4). Some BEs perform NAT on each donation, even on frequent donors' donations, while others restrict it to new donations. NAT is applied to both pools and individuals, and some BEs that used NAT have reverted back to non-NAT because of its relatively low (and debatable) cost-effectiveness (46).

In short, there is significant heterogeneity in stances on the availability of LBCs to patients through organizations and countries' public health policies. Consistent efforts have been made by large bodies such as EDQM, the American Blood Bank Association or the International Society for Blood Transfusion ISBT to define safety and quality parameters that should apply to each issued LBC; however, this is still a range above and beyond which the LBC should not conform to standards; if testing is individual for most infectious markers (and even some are tested in pools), hematological markers are frequently tested by sampling to define quality (4). This is the reason why we call attention here on the false homogeneity of LBCs despite they go by the noun of "standard." This is in sharp contrast to the actual standardization of plasma derivatives obtained from 100 of 1000s of collections and subjected to an industrial processing (47).

\section{DISPARITIES WITHIN ETHICAL CONSIDERATIONS}

Ethics are largely cultural and it is difficult to establish a platform that fits all situations worldwide. Nevertheless, as early as 1975, WHO declared that sustainable efforts should be made by all countries to collect blood from VNRDs. WHO later set the objective of $100 \%$ VNRD by 2020 (the Melbourne Declaration, 2009) (1). The EDQM has also declared itself in favor of a generalized objective of $100 \%$ VNRD where possible (4). The Oviedo Convention (1997), set up under the auspices of the Council of Europe, has established standards for ethics in the field of human rights and dignity, with regard to the use of tissues of human origin (including blood) (48). Nonetheless, many states have been late in signing this convention and others have not yet ratified it. WHO, considering that many countries could not achieve the 2020 VNRD objective, postponed it to 2025 for certain MiddleEastern countries. State WHO and ISBT in its revised code of Ethics, paid and compensated donations should no longer be acceptable; replacement donations remain questionable (49). The issue of paid versus unpaid plasma collection has been challenged by advocates for the plasma fractionation industry $(13,14,16)$ (the case of paid cell donations is still existing in certain countries including Europe but apparently on the decline worldwide). It is worth noting that a very interesting study was published in 2012 questioning the ban on financial contracts with blood donors in Africa, with the declared objective to reduce the infectious burden on "donated" blood (50). This last example questions the universality of ethical values of blood donation when coming to strengthening safety in LBC beneficiaries, opening an additional ethical dilemma. Next, when this comes to plasma for fractionation, there have been requests that collection and fractionation are more equally dispatched in countries that prescribe most to do justice to patients in need in case there is shortage and to alleviate the burden of (paid) collection in countries hosting the majority of plasma collectors such as the USA (51).

We offer an opinion here: as opposed to normative ethics (the Oviedo Convention, the ISBT Code of Ethics), reflective ethics (anthropological and philosophical) are preferred in order to move forward with the safe use (for donors, recipients, stakeholders and society members, i.e. people, civilians and tax payers) of substances of human origin (41). In the meantime, there is clear evidence that ethics are extremely cultural and embedded with acknowledged or hidden religious sentiments with the populations concerned.

In short, it should be noticed that blood within the transfusion process offers an additional paradox: while the LBCs are relatively inhomogeneous relative to active constituents though relatively homogenous relative to the so-called ethicality of their collection, this is the other way around for plasma derivatives that are remarkably homogenous and standardized relative to active constituents but may be obtained both within the profit and the non-for-profit sectors. The latter case has been recently (2016) the subject of important debated in France and Switzerland and journalists reported both in the paper and the TV press on some potential malpractice with respect to donors' own safety and vulnerability.

\section{CONCLUDING REMARKS}

The transfusion process is at the crossroads of a multitude of paradoxes (42). It is one of the only medicines that rely on material outside the control of the pharmaceutical industry if we exclude plasma for fractionation. It professes to be precision medicine, yet the issued LBC comprises $\pm 20 \%$ (or more) of the expected therapeutic constituent. It professes to be personalized medicine, but blood groups between donors and recipients match for the vast minority. It is prescribed for the most fragile patients, yet practitioners prove to have very limited knowledge on it (according to recent surveys, they usually know which is the target of a biosimilar drug or a therapeutic monoclonal antibody, but only largely relative to LBCs) (43). We believe it is important to advocate for prescribing doctors to receive further training on LBCs and transfusion medicine-setting apart the case of standardized plasma derivative or drugs-education and training are essential to understanding and respecting blood donors and donated LBCs, to making wise choices, and to the optimal management of patients' blood and donated LBCs, within the limitations of prevailing uncertainty (Garraud et al., in preparation). Being knowledgeable in the face of uncertainty would prevent a comparison of apples and oranges in published works, even in highquality journals. It would be practical for prescribing doctors to forward their everyday questions to blood transfusion specialists; this would certainly be useful in establishing the most appropriate training programmes.

\section{AUTHOR CONTRIBUTIONS}

Both authors contributed equally to this manuscript and its revision. 


\section{ACKNOWLEDGMENTS}

Both authors would like to thank the research groups to which they belong for their achievements in the fields of blood component characteristics and lesions. They also wish to thank their

\section{REFERENCES}

1. World Health Organization. The Melbourne Declaration on 100\% Voluntary Non-Remunerated Donation of Blood and Blood Components. Available from: http://www.who.int/worldblooddonorday/MelbourneDeclarationWBDD09. pdf (Accessed: November 20, 2017).

2. World Health Organization, Regional Office for the Eastern Mediterranean. Strategic Framework for Blood Safety and Availability 2016-2025. (2016). Available from: http://www.who.int/iris/handle/10665/250402 (Accessed: November 20, 2017).

3. Haddad A, Bou Assi T, Garraud O. Can a decentralized blood system ensure self-sufficiency and blood safety? The Lebanese experience. J Public Health Policy (2017) 38:359-65. doi:10.1057/s41271-017-0076-x

4. EDQM (Council of Europe). Guide to the Preparation, Use and Quality Assurance of Blood Components. 19th ed. Strasbourg, France: EDQM Publishers (2017). $540 \mathrm{p}$.

5. Garraud O, Tissot JD. Theoretical and experimental ethics: advocacy for blood donors and beneficiaries of blood transfusions. Transfus Med (2017). doi:10.1111/tme.12457

6. Garraud O. "Transfusion clinique et biologique" - what makes transfusion medicine and biology so special? Transfus Clin Biol (2017) 24:403. doi:10.1016/ j.tracli.2017.09.002

7. Tissot JD, Garraud O. Ethics and blood donation: a marriage of convenience. Presse Med (2016) 45:e247-52. doi:10.1016/j.lpm.2016.06.016

8. Garraud O, Politis C, Vuk T, Tissot JD. Rethinking transfusion medicine with a more holistic approach. Transfus Clin Biol (2017) 25:439-45. doi:10.1016/j. tracli.2017.10.005

9. Garraud O, Lefrère JJ. Blood and blood-associated symbols beyond medicine and transfusion: far more complex than first appears. Blood Transfus (2014) 12:14-21. doi:10.2450/2013.0131-13

10. World Health Organization. Available from: http://www.who.int/campaigns/ world-blood-donor-day/2017/en/ (Accessed: November 20, 2017).

11. Aldamiz-Echevarria C, Aguirre-Garcia MS. A behavior model for blood donors and marketing strategies to retain and attract them. Rev Lat Am Enfermagem (2014) 22:467-75. doi:10.1590/0104-1169.3398.2439

12. Petrini C. Production of plasma-derived medicinal products: ethical implications for blood donation and donors. Blood Transfus (2014) 12(Suppl 1): s389-94. doi:10.2450/2013.0167-12

13. Farrugia A, Penrod J, Bult JM. The ethics of paid plasma donation: a plea for patient centeredness. HEC Forum (2015) 27:417-29. doi:10.1007/s10730014-9253-5

14. Farrugia A, Del Bò C. Some reflections on the code of ethics of the International society of blood transfusion. Blood Transfus (2015) 13:551. doi:10.2450/2015.0266-14

15. Flanagan P. The code of ethics of the International society of blood transfusion. Blood Transfus (2015) 13:537-8. doi:10.2450/2015.0061-15

16. Farrugia A, Del Bò C. Reply to Flanagan "the code of ethics of the International society of blood transfusion" [blood transfus 2015; 13: 537-8]. Blood Transfus (2017) 15:286-8. doi:10.2450/2016.0013-16

17. Morkeberg J. Blood manipulation: current challenges from an anti-doping perspective. Hematology Am Soc Hematol Educ Program (2013) 1:627-31. doi:10.1182/asheducation-2013.1.627

18. Elghblawi E. Platelet-rich plasma, the ultimate secret for youthful skin elixir and hair growth triggering. J Cosmet Dermatol (2017). doi:10.1111/jocd.12404

19. Gourraud PA, Khankhanian P, Cereb N, Yang SY, Feolo M, Maiers M, et al. HLA diversity in the 1000 genomes dataset. Plos One (2014) 9:e97282. doi:10.1371/journal.pone.0097282

20. De Clippel D, Baeten M, Torfs A, Emonds MP, Feys HB, Compernolle V, et al. Screening for HLA antibodies in plateletpheresis donors with a history of transfusion or pregnancy. Transfusion (2014) 54:3036-42. doi:10.1111/ $\operatorname{trf.} 12727$ colleagues in the field of ethics applied to blood transfusion for their long-term collaboration, as well as the EMITm Think Tank. OG expresses his gratitude to the association Les Amis de Rémi, Savigneux, France, and the Association Recherche et Transfusion, Paris, France for their long-standing support.

21. McGuinn CE, Mitchell BW, Bussel JB. Chapter 91 - Fetal and neonatal alloimmune thrombocytopenia. In: Shaz BH, Hillyer CD, Abrams CS, Roshal M editors. Transfusion medicine and hemostasis: clinical and laboratory aspects. 2nd edn. (2013):609-13. doi:10.1016/B978-0-12-397164-7.00091-4

22. Brouk H, Bertrand G, Zitouni S, Djenouni A, Martageix C, Griffi F, et al. HPA antibodies in Algerian multitransfused patients: prevalence and involvement in platelet refractoriness. Transfus Apher Sci (2015) 52:295-9. doi:10.1016/j. transci.2014.12.028

23. International Societies for Blood Transfusion (ISBT) (2017). Available from: http://www.isbtweb.org/working-parties/red-cell-immunogenetics-andblood-group-terminology/ISBT (Accessed: November 20, 2017).

24. Hendrickson JE, Eisenbarth SC, Tormey CA. Red blood cell alloimmunization: new findings at the bench and new recommendations for the bedside. Curr Opin Hematol (2016) 23:543-9. doi:10.1097/MOH.0000000000000277

25. Körmöczi GF, Mayr WR. Responder individuality in red blood cell alloimmunization. Transfus Med Hemother (2014) 41:446-51. doi:10.1159/000369179

26. Pavenski K, Freedman J, Semple JW. HLA alloimmunization against platelet transfusions: pathophysiology, significance, prevention and management Tissue Antigens (2012) 79:237-45. doi:10.1111/j.1399-0039.2012.01852.x

27. Tzounakas VL, Kriebardis AG, Papassideri IS, Antonelou MH. Donorvariation effect on red blood cell storage lesion: a close relationship emerges. Proteomics Clin Appl (2016) 10:791-804. doi:10.1002/prca.201500128

28. Tzounakas VL, Georgatzakou HT, Kriebardis AG, Voulgaridou AI, Stamoulis KE, Foudoulaki-Paparizos LE, et al. Donor variation effect on red blood cell storage lesion: a multivariable, yet consistent, story. Transfusion (2016) 56:1274-86. doi:10.1111/trf.13582

29. Tzounakas VL, Georgatzakou HT, Kriebardis AG, Papageorgiou EG, Stamoulis KE, Foudoulaki-Paparizos LE, et al. Uric acid variation among regular blood donors is indicative of red blood cell susceptibility to storage lesion markers: a new hypothesis tested. Transfusion (2015) 55:2659-71. doi:10.1111/ trf.13211

30. Acker JP, Marks DC, Sheffield WP. Quality assessment of established and emerging blood components for transfusion. J Blood Transfus (2016) 2016: 4860284. doi:10.1155/2016/4860284

31. Card RT, Mohandas N, Mollison PL. Relationship of post-transfusion viability to deformability of stored red cells. Br J Haematol (1983) 53:237-40. doi:10.1111/ j.1365-2141.1983.tb02016.x

32. D'Alessandro A, Kriebardis AG, Rinalducci S, Antonelou MH, Hansen KC, Papassideri IS, et al. An update on red blood cell storage lesions, as gleaned through biochemistry and omics technologies. Transfusion (2015) 55:205-19. doi:10.1111/trf.12804

33. Burnouf T, Chou ML, Goubran H, Cognasse F, Garraud O, Seghatchian J. An overview of the role of microparticles/microvesicles in blood components: are they clinically beneficial or harmful? Transfus Apher Sci (2015) 53:137-45. doi:10.1016/j.transci.2015.10.010

34. Tissot JD, Bardyn M, Sonego G, Abonnenc M, Prudent M. The storage lesions: from past to future. Transfus Clin Biol (2017) 24:277-84. doi:10.1016/j. tracli.2017.05.012

35. Prudent M, Tissot JD, Lion N. The 3-phase evolution of stored red blood cells and the clinical trials: an obvious relationship. Blood Transfus (2017) 15:188. doi:10.2450/2017.0317-16

36. Klein HG, Cortés-Puch I, Natanson C. More on the age of transfused red cells. N Engl J Med (2015) 373:283. doi:10.1056/NEJMc1505699

37. Sanz CC, Pereira A. Age of blood and survival after massive transfusion. Transfus Clin Biol (2017) 24:449-53. doi:10.1016/j.tracli.2017.04.005

38. Gehrie EA, Tobian AAR. Finally, what we have been waiting for: evidence that transfusion of RBCs at the extreme of the storage spectrum is safe. Lancet Haematol (2017) 4:e504-5. doi:10.1016/S2352-3026(17)30179-5

39. Garraud O. Hemolysis in six week-old autologous red blood cell components questioned: worth addressing the issue of homologous components as well? Transfus Apher Sci (2017) 56:261-2. doi:10.1016/j.transci.2017.03.008 
40. Garraud O, Tissot JD, Vlaar AP. Short-term versus long-term blood storage. N Engl J Med (2017) 376:1091. doi:10.1056/NEJMc1700464

41. Garraud O. Effect of "old" versus "fresh" transfused red blood cells on patients' outcome: probably more complex than appears. J Thorac Dis (2017) 9:E146-8. doi:10.21037/jtd.2017.02.03

42. Parliament of Europe. Directive 2002/98/Ec of the European parliament and of the council of 27 january 2003 setting standards of quality and safety for the collection, testing, processing, storage and distribution of human blood and blood components and amending directive2001/83/EC. Off J Eur Union (2003) L 33/30

43. Parliament of Europe. Directive 2001/83/EC of the European parliament and of the council of 6 november 2001 on the community code relating to medicinal products for human use. Off J Eur Union (2002) L 311.

44. World Health Organisation. 19th WHO Model List of Essential Medicines. (2015). Available from: http://www.who.int/medicines/publications/essentialmedicines/EML2015_8-May-15.pdf (Accessed: November 21, 2017).

45. Garraud O, Tissot JD. Les produits sanguins thérapeutiques: des médicaments ou des produits de santé à part ? Transfus Clin Biol (2016) 23:127-31. doi:10.1016/j.tracli.2016.06.001

46. Borkent-Raven BA, Janssen MP, van der Poel CL, Bonsel GJ, van Hout BA. Cost-effectiveness of additional blood screening tests in the Netherlands. Transfusion (2012) 52:478-88. doi:10.1111/j.1537-2995.2011. 03319.x

47. Burnouf T. Current status and new developments in the production of plasma derivatives. ISBT Sci Ser (2015) 11:18-25. doi:10.1111/voxs.12269
48. Council of Europe. The Oviedo Convention: Protecting Human Rights in the Biomedical Field (Convention on Human Rights and Biomedicine (ETS No 164)) Strasbourg, France (1997). Available from: https://www.coe.int/en/web/conventions/full-list/-/conventions/treaty/164 (Accessed: November 21, 2017).

49. International Societies for Blood Transfusion (ISBT). The Revised Code of Ethics. (2017). Availale from: http://www.isbtweb.org/fileadmin/user_upload/ ISBT_Code_Of_Ethics_English.pdf (Accessed: November 21, 2017).

50. Ala F, Allain JP, Bates I, Boukef K, Boulton F, Brandful J, et al. External financial aid to blood transfusion services in sub-Saharan Africa: a need for reflection. PLoS Med (2012) 9:e1001309. doi:10.1371/journal.pmed.1001309

51. Strengers PF, Klein HG. Plasma is a strategic resource. Transfusion (2016) 56:3133-7. doi:10.1111/trf.13913

Conflict of Interest Statement: The authors declare that the research was conducted in the absence of any commercial or financial relationships that could be construed as a potential conflict of interest.

The reviewer PT and the handling Editor declared their shared affiliation.

Copyright $\odot 2018$ Garraud and Tissot. This is an open-access article distributed under the terms of the Creative Commons Attribution License (CC BY). The use, distribution or reproduction in other forums is permitted, provided the original author(s) and the copyright owner are credited and that the original publication in this journal is cited, in accordance with accepted academic practice. No use, distribution or reproduction is permitted which does not comply with these terms. 